\title{
BMJ Open Study protocol for a multicentre, prospective cohort study of the association of angiotensin II type 1 receptor blockers on outcomes of coronavirus infection
}

\author{
James A. Russell (D) , J John C Marshall, ${ }^{2}$ Arthur Slutsky, ${ }^{3}$ Srinivas Murthy, ${ }^{4}$ \\ Dave Sweet, ${ }^{5}$ Terry Lee, ${ }^{6}$ Joel Singer, ${ }^{6}$ David M Patrick, ${ }^{6}$ Bin Du, ${ }^{7}$ \\ Zhiyong Peng (D) , ${ }^{8}$ Matthew Cheng, ${ }^{9}$ Kevin D Burns, ${ }^{10}$ Michael O Harhay (1) ${ }^{11}$
}

To cite: Russell JA, Marshall JC, Slutsky A, et al. Study protocol for a multicentre, prospective cohort study of the association of angiotensin II type 1 receptor blockers on outcomes of coronavirus infection. BMJ Open 2020;10:e040768. doi:10.1136/ bmjopen-2020-040768

- Prepublication history and additional material for this paper are available online. To view these files, please visit the journal online (http://dx.doi. org/10.1136/bmjopen-2020040768).

Received 31 May 2020 Revised 18 August 2020 Accepted 09 September 2020

Check for updates

(C) Author(s) (or their employer(s)) 2020. Re-use permitted under CC BY-NC. No commercial re-use. See rights and permissions. Published by BMJ.

For numbered affiliations see end of article.

Correspondence to

Dr James A. Russell;

jim.russell@hli.ubc.ca

\section{ABSTRACT}

Introduction The COVID-19 epidemic grows and there are clinical trials of antivirals. There is an opportunity to complement these trials with investigation of angiotensin II type 1 receptor blockers (ARBs) because an ARB (losartan) was effective in murine influenza pneumonia.

Methods and analysis Our innovative design includes: ARBs; alignment with the WHO Ordinal Scale (primary endpoint) to align with other COVID-19 trials; joint longitudinal analysis; and predictive biomarkers (angiotensins I, 1-7, II and ACE1 and ACE2). Our hypothesis is: ARBs decrease the need for hospitalisation, severity (need for ventilation, vasopressors, extracorporeal membrane oxygenation or renal replacement therapy) or mortality of hospitalised COVID-19 infected adults. Our two-pronged multicentre pragmatic observational cohort study examines safety and effectiveness of ARBs in (1) hospitalised adult patients with COVID-19 and (2) out-patients already on or not on ARBs. The primary outcome will be evaluated by ordinal logistic regression and main secondary outcomes by both joint longitudinal modelling analyses. We will compare rates of hospitalisation of ARB-exposed versus not ARB-exposed patients. We will also determine whether continuing ARBs or not decreases the primary outcome. Based on published COVID-19 cohorts, assuming $15 \%$ of patients are ARB-exposed, a total sample size of 497 patients can detect a proportional OR of 0.5 (alpha $=0.05,80 \%$ power) comparing WHO scale of ARBexposed versus non-ARB-exposed patients.

Ethics and dissemination This study has core institution approval (UBC Providence Healthcare Research Ethics Board) and site institution approvals (Health Research Ethics Board, University of Alberta; Comite d'etique de la recerche, CHU Sainte Justine (for McGill University and University of Sherbrook); Conjoint Health Research Ethics Board, University of Calgary; Queen's University Health Sciences \& Affiliated Hospitals Research Ethics Board; Research Ethics Board, Sunnybrook Health Sciences Centre; Veritas Independent Research Board (for Humber River Hospital); Mount Sinai Hospital Research Ethics Board; Unity Health Toronto Research Ethics Board, St. Michael's Hospital). Results will be disseminated by peerreview publication and social media releases.

\section{Strengths and limitations of this study}

- We have four strengths: first, our innovative design includes evaluation of use of angiotensin receptor blockers (ARBs) and aligns with the WHO Ordinal Scale (primary endpoint) to align with other COVID-19 trials.

- Second, we will use adjusted ordinal logistic regression to assess the primary outcome (COVID-19 WHO Ordinal Scale) and adjusted regression analysis for the secondary outcomes.

- Third, we measure and evaluate several biomarkers (angiotensins I, 1-7, II and ACE1 and ACE2) that are predictive of outcomes and response to ARBs in COVID-19.

- Fourth, our two-pronged multicentre pragmatic observational cohort study will determine the safety and effectiveness of ARBs in ${ }^{1}$ (1) hospitalised adult patients with COVID-19 and ${ }^{2}$ (2) out-patients, already on or not on ARBs.

- The limitations are that the study is not randomised and not blinded.

Trial registration number NCT04510623

\section{INTRODUCTION}

The coronavirus (COVID-19) epidemic grows, mortality rate is $2 \%$ (lower than Severe Acute Respiratory Syndrome (SARS) (10\%) and Middle East Respirtatory Syndrome (MERS) $(36 \%)$ ) but is $10 \%$ in hospitalised and $24 \%-62 \%^{1}$ in ICU-admitted patients in China. ${ }^{2-4}$ Interventions to date include quarantine, isolation and usual clinical care. There are no proven vaccines and just one antiviral-remdesivir ${ }^{5}$ - is approved for COVID19. However, the critical illness complications of COVID-19—septic shock, acute respiratory distress syndrome (ARDS) and acute kidney 
injury (AKI) - are caused in part by the host response. We have a unique opportunity to complement these trials of antivirals with investigation of modulation of the host response to improve outcomes of COVID- $19 .{ }^{67}$

Publications at the time of our grant submission were used to derive power and sample size. Of 278 COVID-19 hospitalisations in China ${ }^{2-4}$ at that time, $7 \%$ had septic shock, 20\% ARDS, 9\% needed intubation and ventilation, $3 \%$ needed extracorporeal membrane oxygenation, $7 \%$ had AKI, 5\% needed renal replacement therapy (RRT) and 8\% died. Critically ill patients with COVID-19 have similar mortality as sepsis and ARDS. Mortality of ICU-admitted patients with COVID- $19^{3}{ }^{4}$ was $2 \%-62 \%,{ }^{8}$ similar to or higher than sepsis mortality (24\% in 101 064 patients in Australia) $)^{9}$ and ARDS mortality (30\% in a systematic review) ${ }^{10}$ Clearly there are opportunities to improve these outcomes.

COVID-19 binds ACE2 ${ }^{11}$ and so the ACE axis is central to septic shock, ARDS and COVID-19. ${ }^{12}$ SARS-CoV-2's spike glycoprotein binds ACE2 10-20 times more avidly than does SARS ${ }^{11}$ and inactivates ACE2. ${ }^{13}$ Patients already on ARBs have lower sepsis mortality and do not have worse haemodynamic status (blood pressure ${ }^{14}$ ) than patients not on ARBs. ${ }^{15-17}$

The underlying mechanisms leading to the acute lung injury after viral infection mediated by an increase in angiotensin $\mathrm{II}^{18}$ (ie, microvascular damage, increased vascular permeability, secondary production of inflammatory cytokines, accelerated apoptosis, fibrosis). Local activation of the renin-angiotensin-aldosterone system may mediate lung and cardiac injury responses to SARS-CoV-2. SARS-CoV-2 infection increases lung and coronary microvascular thrombosis and coagulation (increased D-dimers), which is associated with increased COVID-19 mortality ${ }^{19}$. ATII binds the ATII receptor 1 (AGTR1) which increases expression of tissue factor (TF) and plasminogen activator inhibitor-1 (PAI-1). ${ }^{21}$ Losartan decreases $\mathrm{TF}^{22}$ and PAI-1. ${ }^{22}{ }^{23}$ ARBs may also modulate ACE2 activity ${ }^{24}$ upregulating ACE2 in cardiac tissue ${ }^{25}$ and that could be an adverse effect of ARBs in COVID-19.

The most severe cases of COVID-19 that require ICU care have ARDS, septic shock and AKI. We also have had success in discovery of off-target drugs: proprotein convertase subtilisin/kexin type 9 inhibition ${ }^{26-28}$ and cholesteryl ester transfer protein inhibition ${ }^{29-31}$ for sepsis. Determining whether plasma angiotensin I, 1-7 and II and ACE and ACE2 levels predict response to ARBs is based on our genomics and protein biomarker research in which we identified predictive biomarkers (ie, predictive of response to angiotensin $\mathrm{II}^{32}{ }^{32}$ vasopressin, ${ }^{33}$ and norepinephrine $\left.{ }^{34}\right)$.

There is clinical equipoise regarding safety and effectiveness of ARBs in COVID-19. ${ }^{35-37}$ At the time of our study design and implementation there was only one study that separated ARBs use from ACE inhibitor (ACEi) use ${ }^{38} 39$ $(n=362)$ finding no associations of ARBs or ACEi with mortality. ${ }^{38} \mathrm{~A}$ recent meta-analysis found that use of ARBs or ACEi use was associated with decreased mortality of
COVID-19. ${ }^{40}$ ARBs or ACEi use in patients with COVID-19 with hypertension $(\mathrm{n}=1128)$ was associated with decreased mortality $(9.8 \%$ vs $3.7 \%$, RRR $60 \%, p=0.03)$ compared with patients not on ARBs/ACEis in one study ${ }^{41}$ but not in Feng and colleagues. ${ }^{42} \mathrm{Li}$ and colleagues ${ }^{38}$ found no differences in use of ACEis (9.1\% vs 9.8\%; $p=0.85)$, ARBs ( $19.5 \%$ vs $23.9 \%$; $\mathrm{p}=0.42$ ), or the composite ACEis/ARBs $(27.3 \%$ vs $33.0 \% ; \mathrm{p}=0.34)$ between non-survivors and survivors.

Losartan (an ARB) decreases viral replication and lung injury in murine influenza pneumonia. ${ }^{8}$ ARBs are inexpensive clinically-available drugs used in hypertension and heart failure that could decrease morbidity and mortality of COVID-19. Angiotensin II worsens lung injury in influenza models ${ }^{2-4}$ because ACE2 is downregulated in H1N1, H5N1, H7N9 and SARS ${ }^{2-4} 43$ leading to increased angiotensin II. Angiotensin II levels are increased in COVID- $19^{44}$ and human influenza and are associated with influenza viral load, disease progression and mortality. ${ }^{45}$ Losartan limits lung injury in murine influenza H7N9(8), viral titre and RNA and lung injury. ARBs could limit viral titre and organ injury.

Hypertension guidelines recommend ARBs if ACEis are not tolerated, ${ }^{46}$ are very commonly prescribed (59\% of hypertension ${ }^{47}$ ), $35 \%$ of hypertensive patients with chronic kidney disease $(\mathrm{CKD})^{48}$ and $32 \%$ of diabetics. ${ }^{49}$ ARBs are recommended first line therapy in Canadian heart failure guidelines. ${ }^{50}$ In Alberta, Canada, ARBs or ACEis were used in $50 \%-70 \%$ of patients with heart failure $^{51}$ and $58 \%$ of patients in $\mathrm{Nepal}^{52}$ and $52 \%{ }^{53}$ of US patients with heart failure.

If ARBs protect patients from COVID-19 because they are less sick and are not hospitalised, we may detect this in our study of hospitalised COVID-19. Thus, once hospitalised, ARB-exposed patients may not fare better than patients not on ARBs (ie, ARBs may protect them from getting sick enough to be admitted). To address that possibility, we collaborate with SM and his study of community COVID-19 (COVID-19: Improving the Evidence to Treat an Emerging Infection) to determine whether ARB treatment compared with not being on ARBs decreases the risk of hospitalisation.

Initially when we designed our study (ie, before the amendment), we sought to evaluate ARBs treatment versus no ARBs treatment but not ACEis because the available evidence in previous animal studies used ARB for attenuation of acute lung injury. We added an amendment to similarly evaluate ACEi treatment versus no ACEi treatment and ARBs/ACEi versus no ARBs/ACEi.

\section{Overall purpose}

This is a multicentre pragmatic cohort study of hospitalised patients with COVID-19 that leverages cutting-edge longitudinal data analysis methods. We will assess ARBs (losartan, irbesartan, candesartan, telmisartan, valsartan, eprosartan and alzilsartan used to treat hypertension and heart failure) for safety and effectiveness in decreasing need for vital organ support and mortality of hospitalised 


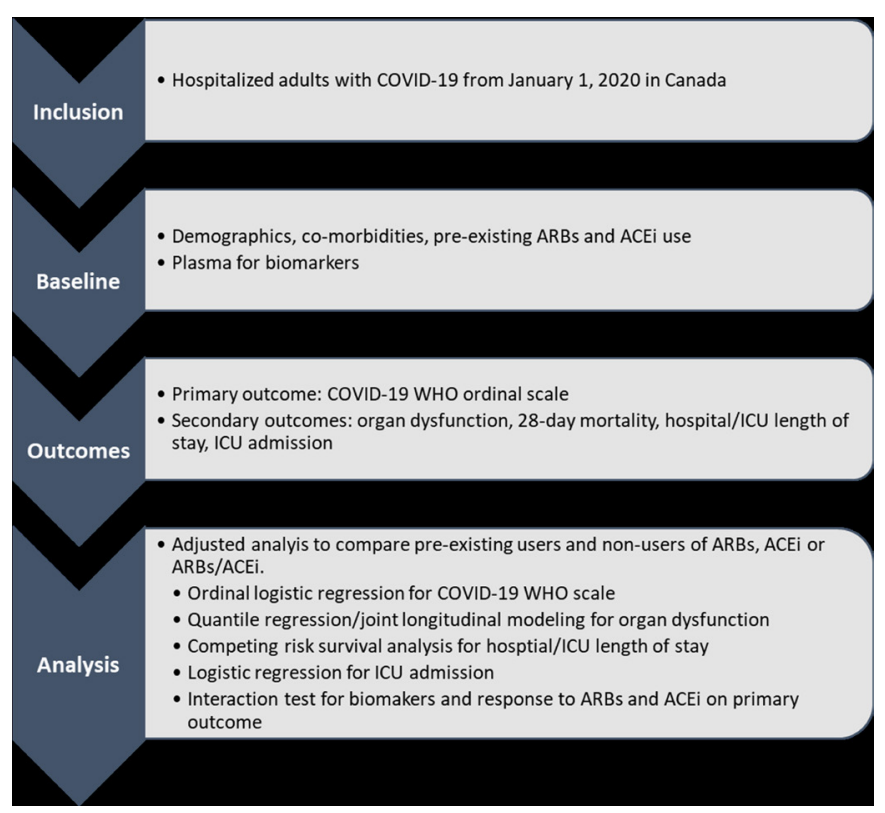

Figure 1 Flow chart of patients. ARBs, angiotensin receptor blockers, ACEi, ACE inhibitor; ARB, angiotensin receptor blockers.

adults with COVID-19. There were two amendments after receiving Canadian Institutes of Health Research (CIHR) funding: to add other ACE pathway biomarkers and to evaluate ACEis (online supplemental file 1). There is a flow chart of ARBs Corona I shown in figure 1.

\section{Objectives}

- To accrue and retrospectively record clinical characteristics and outcomes of COVID-19 hospitalised patients.

- To classify patients as ARB-exposed or not ARB-exposed.

- To measure serum angiotensin II levels at hospital admission and compare to the primary outcome COVID-19 WHO Ordinal Scale as well as comparing ARB-exposed to ARB-non-exposed patients (and ACEi-exposed vs not ACEi-exposed) and the association of these treatments with the outcomes.

- To do adjusted ordinal logistic regression for the primary outcome COVID-19 WHO Ordinal Scale and adjusted regression analysis for the secondary outcomes comparing ARB-exposed to not ARBexposed hospitalised COVID-19 patients.

- To do joint longitudinal analyses of organ dysfunction (as evaluated by the Sequential Organ Failure Assessment (SOFA) Score) over time comparing ARBexposed to not ARB-exposed hospitalised patients with COVID-19.

- To do ordinal logistic regression and interaction tests for the primary outcome COVID-19 WHO Ordinal Scale to determine whether and at what level plasma angiotensin II levels are associated with improved WHO Ordinal Scale in ARB-exposed patients with COVID-19.
- To do logistic regression for the rates of hospitalisation of ARB-exposed to not ARB-exposed patients in the community (in collaboration with SM (COVID19: Improving the Evidence to Treat an Emerging Infection).

- To do ordinal logistic regression subgroup analysis in patients already on ARBs when they are hospitalised to determine whether continuing ARBs (or not) decreases WHO COVID-19 Ordinal Outcome Scale.

Our main hypothesis is that modulation of ACE2 by angiotensin receptor blockers is associated with decreased WHO COVID-19 Ordinal Outcome Scale (that evaluates the severity, need for ventilation, vasopressors, extracorporeal membrane oxygenation or RRT and mortality) of hospitalised COVID-19 infected adults.

\section{Secondary biomarker hypothesis}

Plasma angiotensin II levels are associated with effectiveness of ARBs in hospitalised COVID-19 adults. Secondary HospitalisationHypothesi: odulation of ACE2 by angiotensin receptor blockers is associated with decreased rate of hospitalisation for COVID-19. Secondary Continuing ARBs Hypothesis: In patients already on ARBs when they are hospitalised continuing ARBs is associated with decreased WHO COVID-19 Ordinal Outcome Scale.

\section{METHODS AND ANALYSIS}

Design, participants and timeframe of enrollment and visits Our pragmatic multicentre cohort study comparing $\mathrm{ARB}$ use to no ARB use in COVID-19 is relatively simple, inexpensive, will be done quickly and thus addresses the urgency of COVID-19 research. We will compare outcomes of hospitalised adult patients with COVID-19 (1) who have use of any ARB within 24 hours of onset of COVID-19 symptoms with (2) patients who were not exposed to ARBs. At hospital admission we will obtain discarded blood from the routine blood work ${ }^{33} 3454$ to measure plasma ACE pathway levels (see online supplemental file 1 regarding amendment) and do ordinal logistic regression of the interaction of plasma ACE pathway levels and ARB-exposed or not. For the hospitalisation hypothesis, we will obtain relevant data from SM's CIHR-funded study: 'COVID-19: Improving the Evidence to Treat an Emerging Infection' and do logistic regression for the rates of hospitalisation of ARB-exposed to not ARB-exposed patients in out-patients. For the continuing ARBs or ACEi hypothesis, we will do ordinal logistic regression subgroup analysis in patients on ARBs (or ACEi) when hospitalised to determine whether continuing ARBs (or ACEi, or not) decreases WHO COVID-19 Ordinal Outcome Scale.

Inclusion criteria are individuals over 18 years of age who have confirmed COVID-19 infection (according to local hospital or provincial laboratories clinically approved laboratory testing for COVID-19). ARBsexposed and ACEi-exposed patients are defined for inclusion by being on ARB or ACE prior to and at the time of 
Table 1 Numbers of patients and per cent of patients who had WHO Ordinal Scale of 6, 7 or 8 (needed ventilation, vasopressors, RRT, ECMO or who died) in three publications ${ }^{2-4}$ regarding hospitalised patients in China who had COVID-19 used to derive sample size estimates to detect a one point or greater decrease of the WHO scale of ARB-exposed hospitalised patients compared with a control group of hospitalised patients with no ARB exposure

\begin{tabular}{llllll}
\hline Publication & Admitted to hospital & WHO=6 & WHO=7 & WHO=8 & WHO 6-8 \\
\hline Chen-Lancet & 99 & 4 & 4 & 11 & 19 \\
Wang-JAMA & 138 & 17 & 13 & 6 & 36 \\
Huang-Lancet & 41 & 4 & 3 & 6 & 13 \\
Totals & 278 & 25 & 20 & 23 & 68 \\
$\%$ & & 9.0 & 7.2 & 8.3 & 24.5 \\
\hline
\end{tabular}

RRT, renal replacement therapy.

the hospital admission for COVID-19. There are no exclusion criteria. We will enrol from 1 January 2020 until the conclusion of the COVID-19 epidemic at the centres in Canada (expected mid to end 2021).

\section{Recruitment and power-sample size estimation}

We used published cohorts of hospitalised adults with COVID-19 in China $^{2-4}$ to determine expected severity and sample size. About $32 \%$ have WHO Ordinal Scale criteria 6-8 (vasopressors, ventilation, ECMO, RRT or death). Since about $30 \%$ of patients with COVID-19 had cardiovascular disease or hypertension ${ }^{2-4}$ it is conceivable that a significant proportion of the population could be on ARBs. Assuming that $50 \%$ of the $30 \%$ with cardiovascular disease are on an ARB, then about $15 \%$ of patients of the total cohort would be on an ARB. Ordinal logistic regression will be used to compare the primary outcome-WHO Ordinal Scale for COVID-19-in ARB-exposed versus non-ARB-exposed hospitalised patients. Based on data from three publications (tables 1 and 2), assuming $15 \%$ of the patients were ARB-exposed, a total sample size of 497 can detect a proportional OR of 0.5 (table 2, translated change in proportion in each category of the scale) at alpha $=0.05$ with $80 \%$ power for the comparison of WHO scale in five categories (WHO Ordinal Scale categories:
$3-4,5,6,7$ and 8). The current sample size was selected for feasibility as there was no existing information available to determine the potential effect of ARB exposure on the WHO Ordinal Scale. Calculation was performed using posamsize in the Hmisc package of R 3.6.2 (R Foundation for Statistical Computing, Vienna, Austria).

\section{Exam/visit components, measurements of exposure and disease and other measurements}

Our Case Report Form is adapted from the ISARIC WHO Novel Coronavirus (nCoV) Acute Respiratory Infection Clinical Characterisation Data Tool (https://www.who. int/emergencies/diseases/novel-coronavirus-2019/technical-guidance/early-investigations) because measurements are clinically available and our data will align with other studies of COVID-19.

We will record baseline characteristics (age, gender, heart rate, respiratory rate, temperature, blood pressure, $\mathrm{SaO}_{2}$, respiratory $\left(\mathrm{PaO}_{2} / \mathrm{FiO}_{2}\right)$, creatinine and bilirubin, use of oxygen, vasopressors, ventilation and RRT. Use of ARBs is defined by taking an ARB up to within 24 hours of onset of COVID-19 symptoms. We will also record whether ARBs are continued after onset of symptoms and for how long.

Table 2 Sample size by proportional OR of ARB-exposed versus non ARB-exposed (five categories for WHO scale)

\begin{tabular}{|c|c|c|c|c|c|c|c|c|c|c|}
\hline & \multicolumn{5}{|c|}{ Proportion of patients } & \multirow{2}{*}{$\begin{array}{l}\text { Mean score } \\
\text { All patientst }\end{array}$} & \multicolumn{3}{|c|}{$\begin{array}{l}\text { Total sample size* } \\
\text { (by \% ARB exposed) }\end{array}$} & \multirow[b]{2}{*}{$50 \%$} \\
\hline & WHO 3-4 & WHO 5 & WHO 6 & WHO 7 & WHO 8 & & $10 \%$ & $15 \%$ & $20 \%$ & \\
\hline Non-ARB exposed & 0.604 & 0.151 & 0.090 & 0.072 & 0.083 & 4.577 & & & & \\
\hline \multicolumn{11}{|l|}{ ARB exposed } \\
\hline $\mathrm{OR}=0.7$ & 0.685 & 0.129 & 0.071 & 0.054 & 0.060 & 4.330 & 2656 & 1875 & 1494 & 956 \\
\hline $\mathrm{OR}=0.6$ & 0.718 & 0.119 & 0.064 & 0.048 & 0.052 & 4.237 & 1295 & 914 & 729 & 466 \\
\hline $\mathrm{OR}=0.5$ & 0.753 & 0.107 & 0.056 & 0.041 & 0.043 & 4.137 & 704 & 497 & 396 & 253 \\
\hline $\mathrm{OR}=0.4$ & 0.792 & 0.093 & 0.047 & 0.033 & 0.035 & 4.030 & 403 & 284 & 227 & 145 \\
\hline $\mathrm{OR}=0.3$ & 0.836 & 0.076 & 0.037 & 0.026 & 0.026 & 3.914 & 233 & 165 & 132 & 84 \\
\hline
\end{tabular}

${ }^{*}$ Total size sample referred to the total of ARB exposed and non-ARB exposed.

†Assuming patients were evenly distributed across the WHO 3-4 categories. 
Table 3 WHO 2019-nCoV Ordinal Outcome Scale (J Marshall, personal communication, and Cao and colleagues ${ }^{73}$ )

\begin{tabular}{ll}
\hline Uninfected & 0 points \\
\hline Ambulatory - no limitation of activities & 1 point \\
\hline Ambulatory - limitation of activities & 2 points \\
$\begin{array}{l}\text { Hospitalised-no oxygen (mild) } \\
\text { Hospitalised-oxygen (mild) }\end{array}$ & 3 points \\
$\begin{array}{l}\text { Hospitalised (severe) non-invasive } \\
\text { ventilation or high-flow oxygen }\end{array}$ & 5 points \\
$\begin{array}{l}\text { Hospitalised (severe) intubation and } \\
\text { ventilation }\end{array}$ & 6 points \\
$\begin{array}{l}\text { Hospitalised (severe) ventilation and } \\
\text { additional organ support (vasopressors, } \\
\text { RRT, ECMO) }\end{array}$ & 7 points \\
Death & 8 points \\
\hline
\end{tabular}

nCoV, novel coronavirus; RRT, renal replacement therapy.

The primary outcome is the COVID-19 WHO Ordinal Scale (table 3, J Marshall, personal communication).

Secondary outcomes are SOFA score ${ }^{55}$ (for joint longitudinal modelling), 28-day mortality, hospital length of stay, proportions admitted to ICU, ICU length of stay, need for ventilation, vasopressors and RRT (ie, days alive and free of ventilation, vasopressors and RRT within 14 days $^{56}$ ) and severe adverse effects of ARBs. Comparison of ARB-exposed versus non ARB-exposed will be done by ordinal logistic regression analysis for the primary outcome and by logistic regression for binary secondary outcomes. Time to death and hospital length of stay will be analysed simultaneously using competing risk survival analysis. Given the heavily skewed distribution for days alive and free of ventilation/vasopressors/RRT, the comparison of these outcomes will be done based on quantile regression. Patients who die within the first 14 days will be assigned a value of 0 to maximise penalty for non-survival. No adjustment for multiplicity of inferences will be made for the secondary outcomes given the hypothesis generating nature of these analyses.

\section{Adequacy of ARB intervention timing on COVID-19}

ARB intervention in our study will have been for monthsyears before COVID-19 infection, optimising beneficial effects of ARB on COVID-19 replication, inflammation and permeability. In murine models, the ARB losartan was effective when given 30 min before $\mathrm{H} 7 \mathrm{~N}^{8}$; recombinant ACE2 was effective when given 3 hours prior, 8 hours and 3 days after murine $\mathrm{H} 5 \mathrm{~N} 1{ }^{57}$ Clinicians are often uncertain whether to continue ARBs in patients hospitalised for non-cardiovascular conditions. Thus, in a subgroup analysis of patients already on ARBs when hospitalised, we will evaluate whether continuing ARBs or ACEi (the ARB or ACEi they were already on) or not decreases WHO COVID-19 Ordinal Outcome Scale.
Data management and statistical analyses

DAF vasopressors, ventilation and RRT will be calculated separately by subtracting the number of days on vasopressors, ventilation or RRT from the lesser of 14 or the number of days to death, scored as 1 if the patient is alive and free of vasopressors, ventilation or $\mathrm{RRT}^{56}$ and zero (0) if the patient had vasopressors, ventilation or RRT or is not alive (to maximise non-survival penalty).$^{56}$

We will evaluate ARB-exposed versus not ARB-exposed and ACEi-exposed and not ACEi-exposed. The ACEiexposed versus not ACEi-exposed patient analyses will be done exactly as described for the ARBs-exposed versus not ARBs-exposed patients. There will be a third analysis which compares ARB/ACEi versus no ARB/ACEi. All analyses will be adjusted for potential confounders (age, biological sex, blood pressure, and presence of heart failure, hypertension, renal failure and diabetes (the most common comorbidities of $2019 \mathrm{nCoV}^{2-4}$ associated with increased risk of ICU admission ${ }^{4}$ ) using regression techniques rather than matching (eg, Propensity Score) because of the potential limited sample size and the possibility of discarding valuable data due to unmatched cases).

About $25 \%$ of patients with COVID-19 have organ dysfunction requiring critical care support. Comparisons of organ dysfunction are susceptible to bias from informative censoring (death, discharge, other competing risks $^{58-61}$ ). Joint models handle data that is biassed from informative censoring by simultaneous estimation of two separate regression models with a shared random effect. ${ }^{62}{ }^{63}$ Joint modelling of the longitudinal and survival processes allows each model to inform (ie, adjust) the other to mitigate potential biases caused by missing outcomes (eg, death). Joint longitudinal modelling of SOFA requires estimation of an unobserved SOFA trajectory, estimating the SOFA trajectory if there was no informative censoring. The most common joint models are longitudinal (eg, repeated measures or mixed-effects models) and time-to-event (survival) models.

We will compare ARB-exposed to not ARB-exposed patients' SOFA score by fitting (i) a traditional linear mixed-effects model (ie, longitudinal model with a participant random-intercept) and (ii) several joint longitudinal and survival models of SOFA scores over time. ${ }^{64}$ Time-toevent survival data will be modelled using a Cox proportional hazards model for death; discharge and day 14 will be considered censoring events in death-specific Cox model. Shared random effects will be used to capture the association between the longitudinal and time-to-event models. We will explore multiple model specifications for the joint model by varying the functional form of time in both the fixed effects in the longitudinal component and the shared random effects specifications. For instance, we will test linear and quadratic effects, and spline terms with an increasing number of knots (up to 7 and 2 for the fixed effect and random effect of time, respectively). We will select the final model according to the Akaike Information Criterion and Bayesian Information Criterion. 
Standard errors for the coefficients of the joint model will be estimated via 1000 bootstrap replications, resampling at a participant level. We will test for the modification of treatment by study time by including an interaction term in the longitudinal submodel and by testing its significance using the Wald test. Finally, we will perform several sensitivity analyses to assess the robustness of our findings including fitting a joint model accounting for the competing risk of discharge. All models will be estimated using the joineRML package V.0.4.2 in the statistical software R. ${ }^{65}$ Joint models for longitudinal and survival data can also be implemented in other statistical software such as Stata $^{66}$ and SAS. ${ }^{67}$

We collate in real time and evaluate the the most common severe adverse effects of ARBs: hypotension (systolic pressure $<90 \mathrm{~mm} \mathrm{Hg}$ or mean arterial pressure $<65 \mathrm{~mm} \mathrm{Hg}$ ), hyperkalemia (potassium $>6 \mathrm{mmol} / \mathrm{L}$ ) and AKI (creatinine $>200 \mathrm{mmol} / \mathrm{L}$ ) comparing ARB-exposed with not ARB-exposed patients.

We will examine missing data fields to identify the type of missing data mechanisms. Most data will be missing at random; thus, as a sensitivity analysis, we will use multiple imputation technique to impute the missing data. ${ }^{689}$ Some data will be 'informatively' missing due to clinically relevant events: for example, death, discharge so we will examine statistical models to account for missing not at random (eg, joint longitudinal and timeto-event models, ${ }^{63}$ and inverse probability of censoring weighting $^{70}$ ).

We will evaluate ARB-exposed versus not ARB-exposed, ACEi-exposed versus not ACEi-exposed and ARB/ACEiexposed vs not ARB/ACEi-exposed in ${ }^{1}$ (1) heart failure and hypertension RRT and ${ }^{2}$ (2) patients who do or do not have ARB continued after hospital admission for the primary outcome and DAF vasopressors, ventilation and RRT. Sensitivity analyses will be carried out with adequate adjustments for missing data using multiple imputations technique as described above. The potential bias is that ARBs are not assigned randomly but are given for treatment of hypertension or heart failure thus having a poorer COVID-19 prognosis. We mitigate this bias by doing ordinal logistic regression adjusted analyses to control for confounding by indication and control for variables that increase risk of poor outcomes. We will do analyses that assess the potential of unmeasured confounding (eg, E-value and other recently developed techniques ${ }^{71}{ }^{72}$ ).

\section{Quality assurance and control plans}

We will monitor $15 \%$ of eCRFs against key primary data. We have a weekly 2-hour Management Committee meeting in which data quality and control is a regular agenda item.

\section{Patient and public involvement}

The development of the research question, outcome measures and design was not informed by patients' priorities, experience and preferences. Patients were not involved in the recruitment to and conduct of the study because this is an inpatient hospital-based cohort study. Patients will be included without consent and all data are anonymised so that patients cannot be informed of the results of the study. Patients will be included in the interpretation and dissemination of results through a relationship with the British Columbia Support Unit.

There are limitations of our study. In this association study we cannot determine causation but will add further evidence regarding ARBs or ACEi use in COVID-19 as a foundation for future RCTs in COVID-19 and other viral epidemics caused by viruses that bind ACE2. Another potential limitation is inadequate sample size. The use of ARBs by COVID-19-infected patients may not be adequately large; yet, $50 \%$ of hospitalised patients with COVID-19 had comorbidities ${ }^{56} 40 \%$ cardiovascular or cerebrovascular disease ${ }^{2}$ in which ARBs are commonly prescribed. There is potential bias regarding ARB confounding by indication that we limit by doing ${ }^{1}$ (1) ordinal logistic regression analyses, ${ }^{2}(2)$ sensitivity analyses and ${ }^{3}$ (3) subgroup analyses to examine consistency of effects of ARBs on COVID-19 outcomes.

RCT(s) of ARBs in COVID-19 are now warranted and we are pleased to indicate that we have been funded by the CIHR for a multicentre randomised controlled trial of an ARB in COVID-19.

\section{ETHICS AND DISSEMINATION}

This study has core institution approval by the Providence Healthcare and University of British Columbia Human Research Committee and individual site institutional approvals. Results will be disseminated by peer-review publication and social media releases.

\section{Author affiliations}

${ }^{1}$ Medicine, The University of British Columbia Faculty of Medicine, Vancouver, British Columbia, Canada

${ }^{2}$ Surgery, University of Toronto, Toronto, Ontario, Canada

${ }^{3}$ Medicine, University of Toronto Faculty of Medicine, Toronto, Ontario, Canada ${ }^{4}$ Paediatrics, University of British Columbia, Vancouver, British Columbia, Canada ${ }^{5}$ Emergency Medicine, The University of British Columbia Faculty of Medicine, Vancouver, British Columbia, Canada

${ }^{6}$ Population and Public Health, University of British Columbia, Vancouver, British Columbia, Canada

${ }^{7}$ Medical ICU, Peking University, Beijing, China

${ }^{8}$ Medicine, Wuhan University Zhongnan Hospital, Wuhan, China

${ }^{9}$ Department of Medicine, McGill University, Montreal, Quebec, Canada

${ }^{10}$ Medicine, Ottawa Hospital Research Institute, Ottawa, Ontario, Canada

${ }^{11}$ Biostatistics, Epidemiology, and Informatics, University of Pennsylvania Perelman School of Medicine, Philadelphia, Pennsylvania, USA

\section{Twitter Srinivas Murthy @srinmurthy99}

Contributors JR wrote the CIHR grant that led to this manuscript, the first draft and the final drafts of this manuscript. JCM, SM, DS, AS, TL, JS, DP, BD, ZP, MC and $\mathrm{MOH}$ contributed to the manuscript and to the $\mathrm{ClHR}$ grant that led to this manuscript. KDB contributed to the manuscript.

Funding This study is funded by a grant from the Canadian Institutes of Health Research (CIHR \#439993). John Boyd is a recipient of a Providence Health Care Research Scholarship. Keith Walley is supported by Canadian Institutes of Health Research (CIHR) Foundation Grant FDN 154311.

Competing interests JR reports patents owned by the University of British Columbia (UBC) that are related to the use of PCSK9 inhibitor(s) in sepsis, and 
related to the use of vasopressin in septic shock and a patent owned by Ferring for use of selepressin in septic shock. JR is an inventor on these patents. JR was a founder, Director and shareholder in Cyon Therapeutics Inc. and is a shareholder in Molecular You Corp. JR reports receiving consulting fees in the last 3 years from: (1) Asahi Kesai Pharmaceuticals of America (AKPA) (was developing recombinant thrombomodulin in sepsis). (2) SIB Therapeutics LLC (developing a sepsis drug). (3) Ferring Pharmaceuticals (manufactures vasopressin and developing selepressin). JR is no longer actively consulting for the following: (4) La Jolla Pharmaceuticals (developing angiotensin II; JR chaired the DSMB of a trial of angiotensin II from 2015-2017). (5) PAR Pharma (sells prepared bags of vasopressin). JR reports having received an investigator-initiated grant from Grifols (entitled 'Is HBP a mechanism of albumin's efficacy in human septic shock?') that was provided to and administered by UBC.

Patient consent for publication Not required.

Provenance and peer review Not commissioned; externally peer reviewed.

Supplemental material This content has been supplied by the author(s). It has not been vetted by BMJ Publishing Group Limited (BMJ) and may not have been peer-reviewed. Any opinions or recommendations discussed are solely those of the author(s) and are not endorsed by BMJ. BMJ disclaims all liability and responsibility arising from any reliance placed on the content. Where the content includes any translated material, BMJ does not warrant the accuracy and reliability of the translations (including but not limited to local regulations, clinical guidelines, terminology, drug names and drug dosages), and is not responsible for any error and/or omissions arising from translation and adaptation or otherwise.

Open access This is an open access article distributed in accordance with the Creative Commons Attribution Non Commercial (CC BY-NC 4.0) license, which permits others to distribute, remix, adapt, build upon this work non-commercially, and license their derivative works on different terms, provided the original work is properly cited, appropriate credit is given, any changes made indicated, and the use is non-commercial. See: http://creativecommons.org/licenses/by-nc/4.0/.

\section{ORCID iDs}

James A. Russell http://orcid.org/0000-0003-1484-7539

Zhiyong Peng http://orcid.org/0000-0002-0849-5648

Michael 0 Harhay http://orcid.org/0000-0002-0553-674X

\section{REFERENCES}

1 Yang X, Yu Y, Xu J, et al. Clinical course and outcomes of critically ill patients with SARS-CoV-2 pneumonia in Wuhan, China: a singlecentered, retrospective, observational study. Lancet Respir Med 2020;8:475-81.

2 Chen N, Zhou M, Dong X, et al. Epidemiological and clinical characteristics of 99 cases of 2019 novel coronavirus pneumonia in Wuhan, China: a descriptive study. Lancet 2020;395:507-13.

3 Huang $\mathrm{C}$, Wang $\mathrm{Y}$, Li X, et al. Clinical features of patients infected with 2019 novel coronavirus in Wuhan, China. Lancet 2020.

4 Wang D, Hu B, Hu C, et al. Clinical characteristics of 138 hospitalized patients with 2019 novel coronavirus-infected pneumonia in Wuhan, China. JAMA 2020;323:1061.

5 Grein J, Ohmagari N, Shin D, et al. Compassionate use of Remdesivir for patients with severe Covid-19. N Engl J Med 2020.

6 Fedson DS. Treating the host response to emerging virus diseases: lessons learned from sepsis, pneumonia, influenza and Ebola. Ann Transl Med 2016;4:421.

7 Yan Y, Liu Q, Li N, et al. Angiotensin II receptor blocker as a novel therapy in acute lung injury induced by avian influenza A H5N1 virus infection in mouse. Sci China Life Sci 2015;58:208-11.

8 Yang $\mathrm{P}, \mathrm{Gu} \mathrm{H}$, Zhao Z, et al. Angiotensin-Converting enzyme 2 (ACE2) mediates influenza H7N9 virus-induced acute lung injury. Sci Rep 2014;4:7027.

9 Kaukonen K-M, Bailey M, Suzuki S, et al. Mortality related to severe sepsis and septic shock among critically ill patients in Australia and New Zealand, 2000-2012. JAMA 2014;311:1308-16.

10 Máca J, Jor O, Holub M, et al. Past and present ARDS mortality rates: a systematic review. Respir Care 2017;62:113-22.

11 Wrapp D, Wang N, Corbett KS, et al. Cryo-Em structure of the 2019nCoV spike in the prefusion conformation. Science 2020;367:1260-3.

12 Zhang H, Penninger JM, Li Y, et al. Angiotensin-Converting enzyme 2 (ACE2) as a SARS-CoV-2 receptor: molecular mechanisms and potential therapeutic target. Intensive Care Med 2020;46:586-90.

13 Hoffmann M, Kleine-Weber H, Schroeder S, et al. SARS-CoV-2 cell entry depends on ACE2 and TMPRSS2 and is blocked by a clinically proven protease inhibitor. Cell 2020;181:271-80.
14 de Roquetaillade C, Jamme M, Charpentier J, et al. Hemodynamic impact of cardiovascular antihypertensive medications in patients with sepsis-related acute circulatory failure. Shock 2020;54:315-20.

15 Hsieh MS, How CK, Hsieh VC, et al. Preadmission antihypertensive drug use and sepsis outcome: impact of angiotensin-converting enzyme inhibitors (ACEIs) and angiotensin receptor blockers (Arbs). Shock 2019.

16 Hsu W-T, Galm BP, Schrank G, et al. Effect of renin-angiotensinaldosterone system inhibitors on short-term mortality after sepsis: a population-based cohort study. Hypertension 2020;75:483-91.

17 Mortensen EM, Restrepo MI, Copeland LA, et al. Impact of previous statin and angiotensin II receptor blocker use on mortality in patients hospitalized with sepsis. Pharmacotherapy 2007;27:1619-26.

18 Henry BM, Vikse J, Benoit S, et al. Hyperinflammation and derangement of renin-angiotensin-aldosterone system in COVID-19: a novel hypothesis for clinically suspected hypercoagulopathy and microvascular immunothrombosis. Clin Chim Acta 2020;507:167-73

19 Zhou F, Yu T, Du R, et al. Clinical course and risk factors for mortality of adult inpatients with COVID-19 in Wuhan, China: a retrospective cohort study. Lancet 2020;395:1054-62.

20 Yin S, Huang M, Li D, et al. Difference of coagulation features between severe pneumonia induced by SARS-CoV2 and non-SARSCoV2. J Thromb Thrombolysis 2020. doi:10.1007/s11239-02002105-8. [Epub ahead of print: 03 Apr 2020].

21 D'Elia JA, Bayliss G, Gleason RE, et al. Cardiovascular-renal complications and the possible role of plasminogen activator inhibitor: a review. Clin Kidney J 2016;9:705-12.

22 Koh KK, Chung W-J, Ahn JY, et al. Angiotensin II type 1 receptor blockers reduce tissue factor activity and plasminogen activator inhibitor type-1 antigen in hypertensive patients: a randomized, double-blind, placebo-controlled study. Atherosclerosis 2004;177:155-60.

23 Liu J, Sun N-L, Yang J, et al. Effects of losartan on fibrinolytic parameters and von Willebrand factor in Chinese subjects with hypertension: a comparative study versus atenolol. J Int Med Res 2009;37:595-600.

24 Sarzani R, Giulietti F, Di Pentima C, et al. Disequilibrium between the classic renin-angiotensin system and its opposing arm in SARS-CoV-2-related lung injury. Am J Physiol Lung Cell Mol Physiol 2020;319:L325-36.

25 Ferrario CM, Jessup J, Chappell MC, et al. Effect of angiotensinconverting enzyme inhibition and angiotensin II receptor blockers on cardiac angiotensin-converting enzyme 2. Circulation 2005;111:2605-10.

26 Leung AKK, Genga KR, Topchiy E, et al. Reduced proprotein convertase subtilisin/kexin 9 (PCSK9) function increases lipoteichoic acid clearance and improves outcomes in gram positive septic shock patients. Sci Rep 2019;9:10588.

27 Topchiy E, Cirstea M, Kong HJ, et al. Lipopolysaccharide is cleared from the circulation by hepatocytes via the low density lipoprotein receptor. PLoS One 2016;11:e0155030.

28 Walley KR, Francis GA, Opal SM, et al. The central role of proprotein convertase subtilisin/kexin type 9 in septic pathogen lipid transport and clearance. Am J Respir Crit Care Med 2015;192:1275-86.

29 Genga KR, Trinder M, Kong HJ, et al. Cetp genetic variant rs1800777 (allele a) is associated with abnormally low HDL-C levels and increased risk of AKI during sepsis. Sci Rep 2018;8:16764.

30 Roveran Genga KTM, Kong HJ, Leung AKK, et al. Cholesterylester transfer protein (CETP) genotype R468Q is associated with increased risk of sepsis-associated acute kidney injury (AKI). Sci Reports 2018.

31 Trinder M, Genga KR, Kong HJ, et al. Cholesteryl ester transfer protein influences high-density lipoprotein levels and survival in sepsis. Am J Respir Crit Care Med 2019;199:854-62.

32 Nakada T-aki, Russell JA, Boyd JH, et al. Association of angiotensin II type 1 receptor-associated protein gene polymorphism with increased mortality in septic shock. Crit Care Med 2011;39:1641-8.

33 Nakada T-A, Russell JA, Wellman H, et al. Leucyl/cystinyl aminopeptidase gene variants in septic shock. Chest 2011;139:1042-9.

34 Nakada T-A, Russell JA, Boyd JH, et al. Beta2-Adrenergic receptor gene polymorphism is associated with mortality in septic shock. Am J Respir Crit Care Med 2010;181:143-9.

35 Danser AHJ, Epstein M, Batlle D. Renin-Angiotensin system blockers and the COVID-19 pandemic: at present there is no evidence to abandon renin-angiotensin system blockers. Hypertension 2020;75:1382-5.

36 Patel AB, Verma A. COVID-19 and angiotensin-converting enzyme inhibitors and angiotensin receptor blockers: what is the evidence? JAMA 2020;323:1769-70. 
37 Vaduganathan $\mathrm{M}$, Vardeny $\mathrm{O}$, Michel T, et al. Renin-AngiotensinAldosterone system inhibitors in patients with Covid-19. N Engl J Med 2020.

38 Li J, Wang X, Chen J, et al. Association of renin-angiotensin system inhibitors with severity or risk of death in patients with hypertension hospitalized for coronavirus disease 2019 (COVID-19) infection in Wuhan, China.. JAMA Cardiol 2020.

39 Mehra MR, Desai SS, Kuy S, et al. Cardiovascular disease, drug therapy, and mortality in Covid-19. N Engl J Med 2020.

40 Zhang X, Yu J, Pan L-Y, et al. ACEI/ARB use and risk of infection or severity or mortality of COVID-19: a systematic review and metaanalysis. Pharmacol Res 2020;158:104927.

41 Zhang P, Zhu L, Cai J, et al. Association of inpatient use of angiotensin converting enzyme inhibitors and angiotensin II receptor blockers with mortality among patients with hypertension hospitalized with COVID-19. Circ Res 2020.

42 Feng Y, Ling Y, Bai T, et al. COVID-19 with different severity: a multicenter study of clinical features.. Am J Respir Crit Care Med 2020.

43 Kuba K, Imai Y, Rao S, et al. A crucial role of angiotensin converting enzyme 2 (ACE2) in SARS coronavirus-induced lung injury. Nat Med 2005:11:875-9.

44 Liu Y, Yang Y, Zhang C, et al. Clinical and biochemical indexes from 2019-nCoV infected patients linked to viral loads and lung injury. Sci China Life Sci 2020;63:364-74.

45 Huang F, Guo J, Zou Z, et al. Angiotensin II plasma levels are linked to disease severity and predict fatal outcomes in H7N9-infected patients. Nat Commun 2014;5:3595.

46 Nerenberg KA, Zarnke KB, Leung AA, et al. Hypertension Canada's 2018 guidelines for diagnosis, risk assessment, prevention, and treatment of hypertension in adults and children. Can J Cardiol 2018;34:506-25.

47 Johansen ME, Yun J, Griggs JM, et al. Anti-Hypertensive medication combinations in the United States. J Am Board Fam Med 2020;33:143-6.

48 Murphy DP, Drawz PE, Foley RN. Trends in angiotensin-converting enzyme inhibitor and angiotensin II receptor blocker use among those with impaired kidney function in the United States. J Am Soc Nephrol 2019;30:1314-21.

49 Ibrahim SL, Jiroutek MR, Holland MA, et al. Utilization of angiotensin converting enzyme inhibitors (ACEI) and angiotensin receptor blockers (ARB) in patients diagnosed with diabetes: analysis from the National ambulatory medical care survey. Prev Med Rep 2016;3:166-70.

50 Ezekowitz JA, O'Meara E, McDonald MA, et al. 2017 comprehensive update of the Canadian cardiovascular Society guidelines for the management of heart failure. Can J Cardiol 2017;33:1342-433.

51 Chiu MH, Miller RJH, Barry R, et al. Kidney function, ACEInhibitor/Angiotensin receptor blocker use, and survival following hospitalization for heart failure: a cohort study. Can J Kidney Health Dis 2018:5:2054358118804838.

52 Ghimire R, Dhungana SP. Evaluation of drugs used in chronic heart failure at tertiary care centre: a hospital based study. J Cardiovasc Thorac Res 2019;11:79-84.

53 Tran RH, Aldemerdash A, Chang P, et al. Guideline-Directed medical therapy and survival following hospitalization in patients with heart failure. Pharmacotherapy 2018;38:406-16.
54 Walley KR, Russell JA. Protein C - 1641 AA is associated with decreased survival and more organ dysfunction in severe sepsis. Crit Care Med 2007;35:12-17.

55 Vincent JL, Moreno R, Takala J, et al. The SOFA (sepsis-related organ failure assessment) score to describe organ dysfunction/ failure. on behalf of the Working group on sepsis-related problems of the European Society of intensive care medicine. Intensive Care Med 1996;22:707-10.

56 Russell JA, Lee T, Singer J, et al. Days alive and free as an alternative to a mortality outcome in pivotal vasopressor and septic shock trials. $J$ Crit Care 2018;47:333-7.

57 Zou Z, Yan Y, Shu Y, et al. Angiotensin-Converting enzyme 2 protects from lethal avian influenza A H5N1 infections. Nat Commun 2014;5:3594.

58 Wang $\mathrm{C}$, Scharfstein DO, Colantuoni E, et al. Inference in randomized trials with death and missingness. Biometrics 2017;73:431-40.

59 Colantuoni E, Scharfstein DO, Wang C, et al. Statistical methods to compare functional outcomes in randomized controlled trials with high mortality. BMJ 2018;360:j5748.

60 Hernán MA, Robins JM. Causal inference. Boca Raton: Chapman \& Hall/CRC, 2017.

61 McConnell S, Stuart EA, Devaney B. The truncation-by-death problem: what to do in an experimental evaluation when the outcome is not always defined. Eval Rev 2008;32:157-86.

62 Asar Özgür, Ritchie J, Kalra PA, et al. Joint modelling of repeated measurement and time-to-event data: an introductory tutorial. Int $J$ Epidemiol 2015;44:334-44.

63 Ibrahim JG, Chu H, Chen LM. Basic concepts and methods for joint models of longitudinal and survival data. J Clin Oncol 2010;28:2796-801.

64 Henderson R, Diggle P, Dobson A. Joint modelling of longitudinal measurements and event time data. Biostatistics 2000;1:465-80.

65 Hickey GL, Philipson P, Jorgensen A, et al. joineRML: a joint model and software package for time-to-event and multivariate longitudinal outcomes. BMC Med Res Methodol 2018;18:50.

66 Crowther MJ, Abrams KR, Lambert PC. Joint modeling of longitudinal and survival data. Stata Journal 2013;13:165-84.

67 Zhang D, Chen M-H, Ibrahim JG, et al. JMFit: a SAS macro for joint models of longitudinal and survival data. J Stat Softw 2016;71:1-3.

68 Little RJ, D'Agostino R, Cohen ML, et al. The prevention and treatment of missing data in clinical trials. N Engl J Med 2012;367:1355-60.

69 O'Neill RT, Temple R. The prevention and treatment of missing data in clinical trials: an FDA perspective on the importance of dealing with it. Clin Pharmacol Ther 2012;91:550-4.

70 Hernán MA, Robins JM. Estimating causal effects from epidemiological data. $J$ Epidemiol Community Health 2006;60:578-86

71 Kasza J, Wolfe R, Schuster T. Assessing the impact of unmeasured confounding for binary outcomes using confounding functions. Int $J$ Epidemiol 2017;46:1303-11.

72 VanderWeele TJ, Ding P. Sensitivity analysis in observational research: introducing the E-Value. Ann Intern Med 2017; 167:268-74.

73 Cao B, Wang Y, Wen D, et al. A trial of Lopinavir-Ritonavir in adults hospitalized with severe Covid-19. N Engl J Med 2020;382:1787-99. 